\title{
Effective soil moisture sampling depth of L-band radiometry: A case study
}

\author{
M.J. Escorihuela ${ }^{\text {a,* }}$, A. Chanzy ${ }^{\text {b }}$, J.P. Wigneron ${ }^{\text {c }}$, Y.H. Kerr ${ }^{\mathrm{d}}$ \\ a Department of Hydrology and Water Resources, isardSAT, Barcelona, Spain \\ b UMR EMMAH, INRA, UAPV, Avignon, France \\ ' INRA, EPHYSE, Bordeaux, France \\ d Centre d'Etudes Spatiales de la BIOsphère, Toulouse France
}

\section{A R T I C L E I N F O}

\section{Article history:}

Received 19 September 2009

Received in revised form 9 December 2009

Accepted 12 December 2009

Available online $\mathrm{xxxx}$

\section{Keywords:}

Soil moisture

Passive microwave

SMOS

Roughness

Sampling depth

\begin{abstract}
A B S T R A C T
The aim of this study is to analyze the influence of the soil moisture sampling depth in the parameterization of soil emission in microwave radiometry at L-band. The analysis is based on brightness temperature, soil moisture and temperature measurements acquired over a bare soil during the SMOSREX experiment. A more detailed profile of surface soil moisture was obtained with a soil heat and water flows mechanistic model. It was found that (1) the soil moisture sampling depth depends on soil moisture conditions, (2) the effective soil moisture sampling depth is shallower than provided by widely used field moisture sensors, and (3) the soil moisture sampling depth has an impact on the calibration of soil roughness model parameters. These conclusions are crucial for the calibration and validation of remote sensing data at L-band.
\end{abstract}

\section{Introduction}

Soil moisture plays a key role in hydrological cycle. It is consequently a key variable for weather forecasting, climate studies, water resources and crop management, and forecasting extreme events. L-band $(21 \mathrm{~cm}, 1.4 \mathrm{GHz})$ microwave radiometry has a high sensitivity to soil moisture and is among the best ways to estimate soil moisture by remote sensing. Other means (higher frequency radiometry, optical domain, active remote sensing) have a larger vulnerability to cloud cover and/or various perturbing factors such as roughness or vegetation cover (Kerr, 2007). As a consequence of recent technical developments, two new satellite missions, the Soil Moisture and Ocean Salinity (SMOS) and the Soil Moisture Active Passive (SMAP), will be providing for the first time global mapping of surface soil moisture based on radiometric measurements at L-band.

The radiative transfer models that simulate soil emission could be roughly divided between the coherent models and non-coherent model approaches. In coherent models approaches, the soil is seen as a layered medium and each layer is characterized by its dielectric constant and temperature. The contribution of each layer to the total soil microwave emission is determined by computing the propagation of a coherent electromagnetic wave, through the layered medium. In

\footnotetext{
* Corresponding author. isardSAT, Parc Tecnològic BCNord, Marie Curie 8 - 14, 08042 Barcelona, Spain. Tel.: +34933505508.

E-mail address: mj.escorihuela@isardSAT.cat (M.J. Escorihuela).
}

the non-coherent models, the soil is usually seen as a single layer with an effective soil moisture and effective temperature.

For operational applications involving microwave radiometry, soil moisture is generally estimated by inverting a simple non-coherent model of soil microwave emission. Raju et al. (1995) compared both approaches of soil modeling and they found that both accurately model soil emission provided that the non-coherent approach uses an appropriate soil moisture depth. They found that for L-band radiometers pertinent soil moisture depth was close to $2.5 \mathrm{~cm}$.

In the framework of the SMOS mission preparation, several sites have been instrumented to calibrate and validate SMOS data when it becomes available. Field and airborne campaigns have been carried out to test, validate and understand better the radiative transfer models at L-band. Some of them have shown that, in order to accurately model soil emission, it was necessary to adjust a roughness parameter as a function of soil moisture. In this way, a linear dependency of soil roughness with soil moisture was found by Escorihuela et al. (2007b) over a bare soil on the SMOSREX site. Similarly, over vegetated areas, it was found that the calibration of the soil emission was essential to retrieve accurate estimates of soil moisture. The soil roughness parameters from field and airborne Lband microwave data over vegetated areas were found to be sensitive to soil moisture during the SMOSREX, the COSMOS and NAFE campaigns (Panciera et al., 2009; Saleh et al., 2006, 2009).

In these sites, surface soil moisture was monitored with sensors that provide an integrated measurement over the $0-5 \mathrm{~cm}$ surface layer. Although the L-band soil moisture sampling depth is expected to be somewhat shallower than $5 \mathrm{~cm}$, this type of sensors are widely used to validate remote sensing data at L-band (Calvet et al., 2007; 
Merlin et al., 2008). This choice is dictated by the geometry of existing moisture sensors, which are difficult to install and maintain near the surface.

Our objective in this paper is to determine whether the parameterization of soil emission was affected by the depth of field soil moisture measurements. In particular, we investigated the relationship between soil roughness model parameters and soil moisture found in several studies (Escorihuela et al., 2007b; Panciera et al., 2009; Saleh et al., 2006, 2009).

\section{Materials and methods}

The SMOSREX experimental site is located in the South of France. The site is equipped with a complete meteorological station that measures precipitation, air temperature, atmospheric pressure, wind speed and direction, infrared and solar radiation and specific humidity. The site consists of two plots a bare soil and natural grass grown in a field left fallow, in this paper only measurements over the bare soil are considered. Soil moisture and temperature profiles were monitored every $30 \mathrm{~min}$ for the whole experiment. Soil moisture is measured by impedance probes installed at different depths between the soil surface and every $10 \mathrm{~cm}$ down to $90 \mathrm{~cm}$ deep. In addition, a set of thermistors was installed at the surface and along the soil profile down to a depth of $90 \mathrm{~cm}$. Local Solar Time (LST) is used as time reference for SMOSREX data. The soil is texturally a loamy soil, with a composition of $17 \%$ clay, $36 \%$ sand, and $47 \%$ silt, a bulk density of $1.4 \mathrm{~g} \mathrm{~cm}^{3}$ and a porosity of $40 \%$ at the surface. Further details concerning the SMOSREX experiment are given in de Rosnay et al. (2006).

In this paper, the data set extending from DOY 133 to DOY 366 in 2004 will be used. This data set has been already used to model soil emission; roughness parameters were found to be dependent on soil moisture (Escorihuela, et al., 2007b).

\subsection{Surface soil moisture profile}

Surface soil moisture was monitored using a set of impedance moisture sensors Delta-T Theta Probe ML2 (mention of manufacturers is for the convenience of the reader only and implies no endorsement on the part of the authors). Surface sensors were vertically installed in the soil, providing an integrated measurement of the soil dielectric constant $\left(K_{\mathrm{TP}}\right)$ between 0 and $5 \mathrm{~cm}$ depth. In order to address the soil moisture spatial variability, there were four replicas of surface probes that were about $2 \mathrm{~m}$ apart. The relationship between $K_{\mathrm{TP}}$ and soil moisture $\left(\Theta_{\mathrm{TP}}\right)$ was established by using field calibration. For that purpose, six soil samples were regularly randomly taken from the experimental field for a wide range of soil moisture conditions. Soil moisture was determined by gravimetry for each sample. The average for the six samples was used to estimate the volumetric soil moisture content at the LEWIS footprint scale. Temperature effects on moisture probes were corrected as in Escorihuela et al. (2007a).

In addition, for this experiment a more detailed profile of soil moisture was obtained with the TEC (Transfert Eau Chaleur) model, a soil heat and water flows mechanistic model (Chanzy \& Bruckler, 1993). This model is based on the Philip and De Vries partial differential equations. These equations account for energy and water flows in partially saturated porous media and account for the liquid and vapor phases of the water reduced to the case of vertical flows. The nonlinear partial differential equations of the soil model are solved by a Galerkin finite element method. At the surface, the boundary conditions are obtained by solving the energy balance using climatic data (air temperature, vapor pressure and wind velocity at a height of $2 \mathrm{~m}$ and short-wave incoming solar radiation). Consequently, moisture and temperature dynamics are driven by the climate conditions. This mechanistic model simulates the changes of water content and temperature profiles under given climatic conditions.
The thermal conductivity was estimated using the De Vries equations (de Vries, 1963) whereas the parameters of the hydraulic functions (retention curve and unsaturated hydraulic conductivity) were fitted to match soil moisture and temperature measurements in the top $10 \mathrm{~cm}$ soil layer.

The model thus allows to obtain a finer description of the surface soil moisture. Surface soil moisture was calculated between 0 to $1 \mathrm{~cm}$ $\left(\Theta_{0-1 \mathrm{~cm}}\right), 0$ to $2 \mathrm{~cm}\left(\Theta_{0-2 \mathrm{~cm}}\right), 0$ to $3 \mathrm{~cm}\left(\Theta_{0-3} \mathrm{~cm}\right)$ and 0 to $5 \mathrm{~cm}\left(\Theta_{0-5} \mathrm{~cm}\right)$ deep and could be computed at any depth down to $90 \mathrm{~cm}$.

\subsection{Surface roughness measurements}

Before the experiment (in November 2003), the soil was slightly randomly ploughed; this work did not produce lines that could be visually observed. Basic roughness parameters were measured on the 4th of February 2004 and on the 2nd of April 2004. Roughness measurements were performed also after the experiment on 13th January 2006.

Soil roughness was characterized by means of a $2-\mathrm{m}$ needle board. The board has 201 needles, $1-\mathrm{cm}$ spacing, which are free to move vertically following the soil elevation profile. Roughness measurements were performed in the along and across directions of the radiometer field of view and replicated six times at each measurement date. The results from these measurements did not show any correlation with the measurement direction. Consequently, the roughness properties are considered to be randomly distributed, and the average value of all replications is considered hereafter. Results from the roughness measurements are shown in Table 1.

A power-curve was fitted with measurements in order to estimate the standard deviation of height $(\sigma)$ during the experiment:

$\sigma[\mathrm{mm}]=-26.11 D O Y^{0.06046}+43.46$.

According to this estimation, during the experiment $\sigma$ would slightly decrease from about $8.4 \mathrm{~mm}$ to $6.1 \mathrm{~mm}$. These measurements indicate that the soil is still evolving after ploughing due to meteorological phenomena (rain and wind). The $\sigma$ ratio to the wavelength $(\lambda=21.4 \mathrm{~cm})$ is quite small, which characterizes a rather smooth soil at this frequency.

\section{Table 1}

Results from roughness measurements over the SMOSREX field. The standard deviation height $(\sigma)$ and correlation length (Lc) are given in $\mathrm{mm}$. Six measurements were performed at each date, the standard deviation of measurements is given between brackets.

\begin{tabular}{lccc}
\hline & 4 Feb 04 & 2 Apr 04 & 13 Jan 06 \\
\hline$\sigma$ & $11.09(3.6)$ & $9.12(2.1)$ & $4.52(1.2)$ \\
Lc & $101.22(42.2)$ & $70.70(33.7)$ & $93.52(37.5)$ \\
\hline
\end{tabular}

\subsection{Radiometric measurements}

Radiometric measurements were obtained by the L-band radiometer for Estimating Water In Soils (LEWIS). LEWIS is a L-band dualpolarization Dicke type radiometer and was specifically designed for the SMOSREX experiment. It is equipped with a Potter horn antenna of $1.3-\mathrm{m}$ diameter, its beam-width at $-3 \mathrm{~dB}$ is $13.6^{\circ}$, and the first side lobes are as low as $-38 \mathrm{~dB}$. The calculated beam efficiency is greater than $98 \%$. The radiometer is thermally regulated at $0.02 \mathrm{~K}$. The instrument resolution is $0.2 \mathrm{~K}$ for a $4 \mathrm{~s}$ integration time, and the estimated absolute calibration accuracy of the instrument is $0.5 \mathrm{~K}$. The instrument is mounted on a 15 -m-high structure. The radiometer features an automatic scan every $3 \mathrm{~h}$ to look at the bare soil at incidence angles from $20^{\circ}$ to $60^{\circ}$ (nadir $=0^{\circ}$ ), and at $\mathrm{H}$ and $\mathrm{V}$ 
polarization. A detailed technical description of the system and its performance can be found in Lemaître et al. (2004).

\subsection{The soil microwave emission model}

Assuming that the air-soil boundary is a plane, the $p$-polarized brightness temperature $\left(T B_{p}\right)$ of a half space with reflectivity $\Gamma_{p}$ (or emissivity $e_{p}, \Gamma_{p}=1-e_{p}$ ) is given by:

$T B_{p}(\phi)=e_{p}(\phi) T_{\text {eff }}+\Gamma_{p}(\phi) T_{\text {sky }}$

where $p$ is the polarization ( $p=v$ or $h$ for the $\mathrm{V}$ and $\mathrm{H}$ polarizations, respectively), $\phi$ is the incidence angle, $e$ is the emissivity, $T_{\text {eff }}$ is the soil effective temperature, $\Gamma$ is the reflectivity, and $T_{\text {sky }}$ is the sky radiometric temperature calculated as in Pellarin et al. (2003).

The soil effective temperature ( $\left.T_{\text {eff }}\right)$ is controlled by the soil dielectric and temperature profiles. It can be expressed as (Ulaby et al., 1986):

$T_{\mathrm{eff}}=\int_{0}^{\infty} T_{\mathrm{s}}(z) W(z) d z$

where $T_{\mathrm{s}}(z)$ is soil thermodynamic temperature at depth $z, W(z)$ is a temperature weighting function of the contribution of each soil layer to the $T_{\text {eff. }} W(z)$ is defined as:

$W(z)=\alpha(z) \cdot \exp \left[-\int_{0}^{z} \alpha\left(z^{\prime}\right) d z^{\prime}\right]$

where

$\alpha(z)=(4 \pi / \lambda) \cdot \epsilon^{\prime \prime}(z) / 2\left(\epsilon^{\prime}(z)\right)^{0.5}$

$\alpha(z)$ is an attenuation coefficient related to the soil dielectric constant, $\lambda$ is the observation wavelength, and $\epsilon^{\prime}$ and $\epsilon^{\prime \prime}$ are the real and imaginary parts of the soil dielectric constant.

The theoretical formulation of the effective temperature requires fine vertical profile information on both soil moisture and soil temperature. The required information is usually not available from remote sensing and several parameterizations have been developed. In this study, soil effective temperature $\left(T_{\text {eff }}\right)$ is parameterized as in Wigneron et al. (2001):

$T_{\text {eff }}=T_{\text {deep }}+\left(T_{\text {surf }}-T_{\text {deep }}\right)\left(w_{\text {surf }} / w_{o}\right)^{b}$

where, $T_{\text {deep }}$ is the soil temperature at $50 \mathrm{~cm}$ depth; $T_{\text {surf }}$ is the soil temperature at $5 \mathrm{~cm}$ depth; $w_{\text {surf }}$ is the volumetric soil moisture at 0 $5 \mathrm{~cm}$ depth; and $w_{o}$ and $b$ were empirically determined in the SMOSREX site $\left(w_{o}=0.32\right.$ and $\left.b=0.58\right)$ showing a rmse of $0.592 \mathrm{~K}$ with theoretical calculations (Holmes et al., 2006).

The temperature sensing (or sampling) depth $\left(\delta_{T}\right)$ is defined as that depth from which $63 \%$ of the radiated energy originates (Ulaby et al., 1986). For the SMOSREX site it can range from a shallow $\delta_{T}$ for March of $8 \mathrm{~cm}$, and a much deeper depth of $27 \mathrm{~cm}$ for July (Holmes et al., 2006).

For a completely flat or specular surface, with a dielectric and temperature homogeneous profile, the reflectivity can be computed with Fresnel equations. In operational applications involving microwave radiometry, the soil reflectivity is calculated from the moisture content at that surface layer. The depth of soil whose dielectric properties determine the surface emissivity is a function of the frequency (or wavelength) and it is called soil moisture sampling depth $\delta_{\mathrm{M}}$. Soil moisture effective sampling depth is $1 / 10 \lambda$ (i.e. $2.1 \mathrm{~cm}$ for L-band) (Ulaby et al., 1986; Wang, 1987). Note that, for wet soils temperature sampling depth is comparable in magnitude to soil moisture sampling depth. For dry soils, however, temperature sampling depth is typically one order of magnitude larger than soil moisture sampling depth (Choudhury et al., 1979; Ulaby et al., 1986).

Soil reflectivity has to account also for surface roughness. In this study, a modified Wang and Choudhury semi-empirical approach is used and the soil reflectivity at $p$ polarization $\left(\Gamma_{p}\right)$ is estimated as in Escorihuela et al. (2007b):

$\Gamma_{p}=\Gamma_{o p} e^{-h \cos } n_{p}(\phi)$

where, $\Gamma_{o p}$ is the Fresnel reflectivity at $p$ polarization; the models proposed by Dobson et al. (1985), Wang and Schmugge (1980), and Mironov et al. (2004) are used to estimate the soil dielectric constant; $n_{p}$ expresses the angular dependency of roughness; over the SMOSREX site Escorihuela et al. (2007b) found $n_{h}=1 n_{v}=-1$; and $h$ is the roughness parameter. Initially Choudhury et al. (1979) proposed $h=(2 k \sigma)^{2}$, where $k$ is the wavenumber, although experimentally, smaller values fit the data better (Wigneron et al., 2001).

\section{Results}

The fitted soil hydraulic functions fell within the range of usual measured properties as given in Chanzy et al. (2008). The TEC model was able to accurately reproduce changes in soil moisture. The comparison between soil moisture measurements by field sensors from 0 to $5 \mathrm{~cm}$ deep $\left(\Theta_{\mathrm{TP}}\right)$ and modeled with the TEC model $\left(\Theta_{0-5 \mathrm{~cm}}\right)$ showed a very good agreement for all moisture conditions (see Fig. 1). The correlation coefficient was $R^{2}=0.93$ and the root mean squared difference was $0.02 \mathrm{~m}^{3} \mathrm{~m}^{-3}$. The small scatter could be explained by errors in the characterization of the soil hydraulic and thermal characteristics and measurement errors, which are mostly higher than $0.01 \mathrm{~m}^{3} \mathrm{~m}^{-3}$ with dielectric techniques after field calibration (Chanzy et al., 1998). Also, although field sensor sensitivity to temperature was corrected, some temperature influence in field measurements could remain introducing differences with model.

The detailed surface soil moisture profile obtained with the TEC model is shown in Fig. 2 for $0-1,0-3$ and $0-5 \mathrm{~cm}$ depths. At the beginning of the experiment (DOY 135) the soil is rather dry showing a very strong soil moisture gradient at the surface. The model seems to saturate for extremely dry soil moisture conditions since values lower than $0.05 \mathrm{~m}^{3} \mathrm{~m}^{-3}$ are not produced. After DOY 300, the soil is wet and there are only slight differences in the simulated soil moisture values between the surface layers, namely the moisture gradient at the surface is very low.

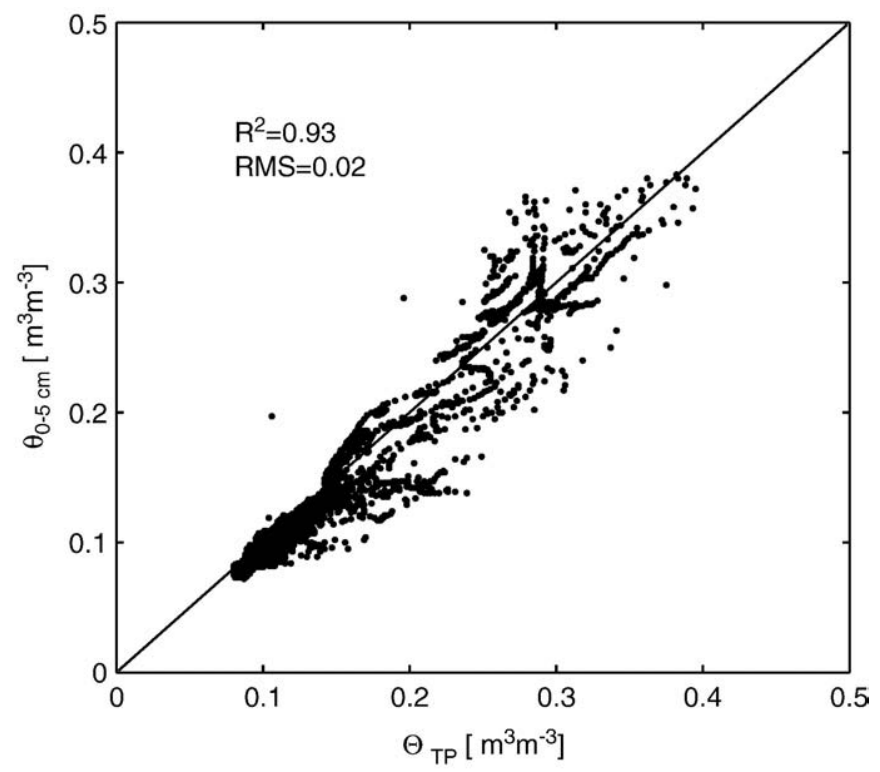

Fig. 1. Correlation between modeled soil moisture $\Theta_{0-5} \mathrm{~cm}$ and measurements from field sensors $\Theta_{\text {TP. }}$ All data throughout the experiment period DOY 133-366 were considered. 


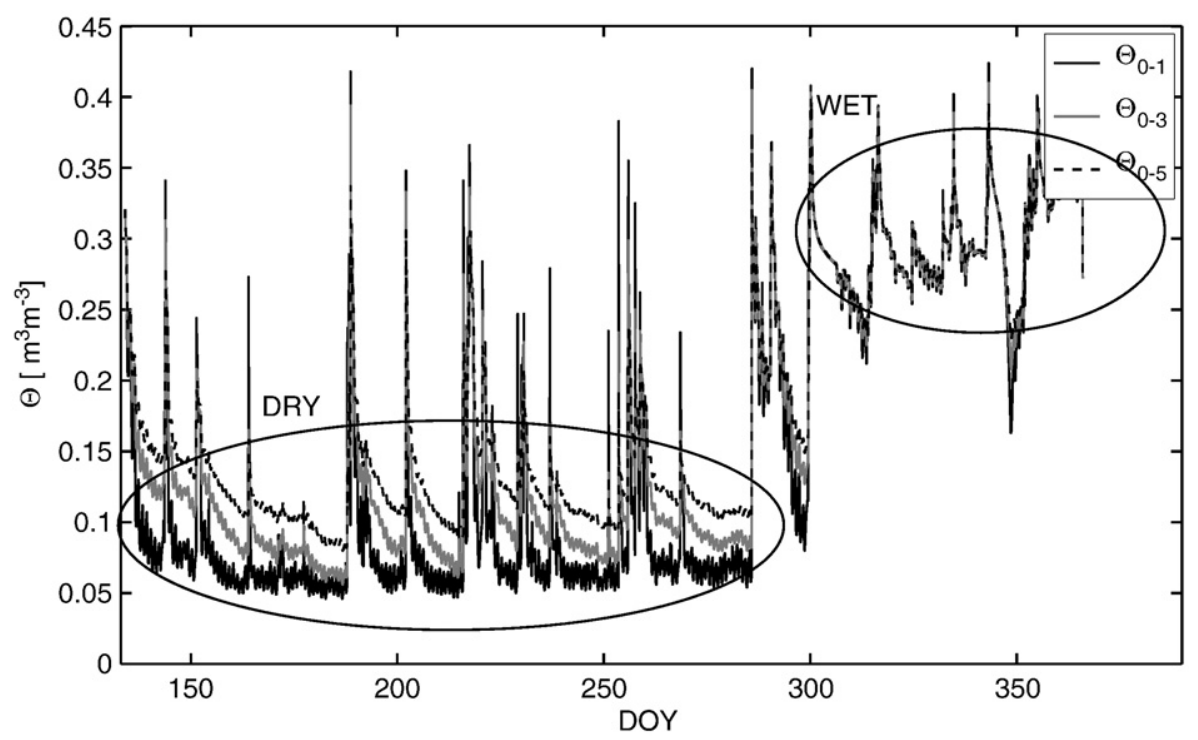

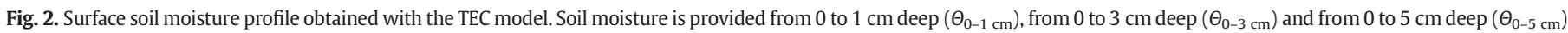
from DOY 135 to 366 in 2004.

In order to empirically assess the soil moisture sampling depth $\left(\delta_{\mathrm{M}}\right)$, the correlation between brightness temperature and surface soil moisture from the different layers was calculated. When correlation between brightness temperature and soil moisture was calculated regardless of soil moisture conditions, the best correlation was found between $T B$ and $\Theta_{0-2 \mathrm{~cm}}$ (not shown), which is in agreement with theory (Raju et al., 1995; Ulaby et al., 1986).

The study was also conducted separately for wet and dry soils. The threshold was set at $\Theta_{\mathrm{TP}}=0.2 \mathrm{~m}^{3} \mathrm{~m}^{-3}$ (see Fig. 2). These results are shown in Table 2 . It can be seen that, the correlation between brightness temperature and $\Theta_{\mathrm{TP}}$ for all soil moisture conditions is lower than for layers closer to the surface. For dry soils, the best correlation was found between brightness temperature and $\Theta_{0-2 \mathrm{~cm}}$. Although at high incidence angles for horizontal polarization, brightness temperature gets more correlated to a slightly deeper soil moisture $(3 \mathrm{~cm})$. For wet soils, although no noticeable difference in moisture between the surface layers can be appreciated in Fig. 2, the brightness temperature was clearly best correlated with $\Theta_{0-1} \mathrm{~cm}$. Soil moisture sampling depth would thus depend on soil moisture conditions. The drier the soil, the deeper the sampling depth. These results are in agreement with the theoretical increase of penetration depth for dry soils (Ulaby et al., 1986).

In order to assess soil emission modeling sensitivity to sampling depth and to the soil dielectric model, soil emission was modeled using

Table 2

Correlation $\left(R^{2}\right)$ between brightness temperature at different angles ( $\phi$ ranging from $20^{\circ}$ to $60^{\circ}$ ) and polarizations ( $\mathrm{V}$ and $\mathrm{H}$ ) and different moisture sampling depths. The threshold between dry and wet soils was set at $\Theta_{\mathrm{TP}}=0.2 \mathrm{~m}^{3} \mathrm{~m}^{-3}$ (see Fig. 2). The best correlation is given in bold characters.

\begin{tabular}{|c|c|c|c|c|c|c|c|c|}
\hline & \multicolumn{4}{|c|}{ Dry soil } & \multicolumn{4}{|c|}{ Wet soil } \\
\hline & $\Theta_{01 \mathrm{~cm}}$ & $\Theta_{02 \mathrm{~cm}}$ & $\Theta_{03 \mathrm{~cm}}$ & $\Theta_{\mathrm{TP}}$ & $\Theta_{01 \mathrm{~cm}}$ & $\Theta_{02 \mathrm{~cm}}$ & $\Theta_{03 \mathrm{~cm}}$ & $\Theta_{\mathrm{TP}}$ \\
\hline V20 & 0.75 & 0.81 & 0.80 & 0.77 & 0.74 & 0.70 & 0.67 & 0.62 \\
\hline V30 & 0.73 & 0.77 & 0.76 & 0.73 & 0.73 & 0.70 & 0.67 & 0.62 \\
\hline V40 & 0.70 & 0.73 & 0.72 & 0.69 & 0.73 & 0.69 & 0.66 & 0.62 \\
\hline V50 & 0.64 & 0.67 & 0.66 & 0.63 & 0.76 & 0.73 & 0.71 & 0.67 \\
\hline V60 & 0.45 & 0.45 & 0.44 & 0.41 & 0.76 & 0.74 & 0.73 & 0.70 \\
\hline $\mathrm{H} 20$ & 0.76 & 0.82 & 0.81 & 0.78 & 0.73 & 0.69 & 0.66 & 0.62 \\
\hline $\mathrm{H} 30$ & 0.75 & 0.80 & 0.80 & 0.77 & 0.72 & 0.68 & 0.65 & 0.61 \\
\hline $\mathrm{H} 40$ & 0.73 & 0.80 & 0.81 & 0.78 & 0.73 & 0.70 & 0.66 & 0.61 \\
\hline $\mathrm{H} 50$ & 0.72 & 0.81 & 0.82 & 0.80 & 0.77 & 0.74 & 0.71 & 0.66 \\
\hline H60 & 0.72 & 0.82 & 0.84 & 0.83 & 0.79 & 0.76 & 0.74 & 0.69 \\
\hline
\end{tabular}

Eqs. (2), (6) and (7) in selected time periods during the experiment. In Eq. (7) different soil moisture sampling depths and dielectric models were used to calculate Fresnel reflectivity $\left(\Gamma_{o p}\right)$ and the $h$ parameter was adjusted to fit soil emission. Time periods with dry and wet soil moisture conditions were selected through the experiment. To ensure the model simulations were accurate, time periods were selected where differences between $\Theta_{0-5 \mathrm{~cm}}$ and $\Theta_{\mathrm{TP}}$ were small $\left(\mathrm{rms}<0.015 \mathrm{~m}^{3} \mathrm{~m}^{-3}\right)$. Extremely dry soil moisture conditions (soil moisture values under $0.08 \mathrm{~m}^{3} \mathrm{~m}^{-3}$ ) were not considered.

During wet periods, no sensitivity of the model roughness parameter to the depth used to estimate soil moisture $\left(\Theta_{\mathrm{TP}}, \Theta_{0-1 \mathrm{~cm}}\right.$, $\Theta_{0-2} \mathrm{~cm}$ and $\Theta_{0-3 \mathrm{~cm}}$ considered) was found (see Fig. 3). It is likely that the low dependency of the roughness parameter to the sampling depth can be attributed to the very low moisture gradient for wet soil moisture conditions. Conversely, during dry periods the model roughness parameter $h$ was found to be sensitive to the depth used to estimate soil moisture. Regardless of the dielectric model, the value of $h$ increased with larger soil moisture depth. This is attributed to the

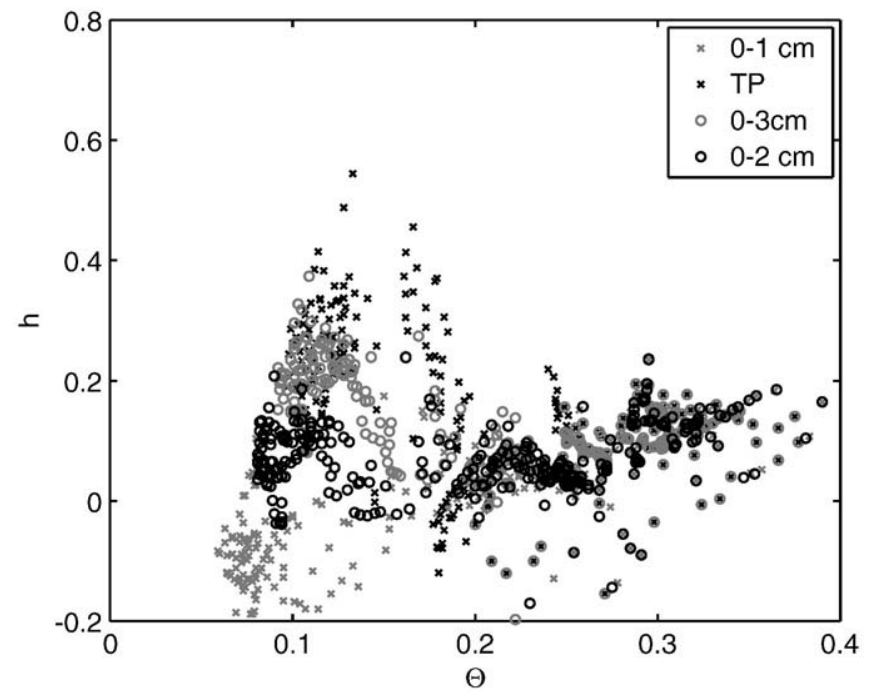

Fig. 3. Roughness model parameter $(h)$ sensitivity to soil moisture sampling depth $\left(\Theta_{0-1 \mathrm{~cm}}, \Theta_{0-2 \mathrm{~cm}}, \Theta_{0-3 \mathrm{~cm}}\right.$ and $\left.\Theta_{\mathrm{TP}}\right)$ using the Mironov model to compute soil dielectric constant in Eq. (7). 
fact that, in dry soil moisture conditions, soil moisture near the surface is always drier than in deeper layers. Consequently, brightness temperature calculated with a moisture layer which is larger than the sampling depth, would have a lower emissivity than the measured one. The roughness parameter $h$ increasing with drier soil moisture conditions would balance the low soil moisture dynamic range (and the low emissivity dynamic range as a result).

Conversely, when simulations were performed with $\Theta_{0-1 \mathrm{~cm}}, h$ slightly decreased to compensate for the underestimation of soil moisture that leads to overestimate brightness temperature. The lowest sensitivity of $h$ on soil moisture was found when the estimated sampling depth (i.e. $\Theta_{0-2} \mathrm{~cm}$ ) was used. These results clearly show that $h$ performs a balance role of emissivity. When emissivity was calculated with a layer thickness larger than the effective sampling depth (about $2 \mathrm{~cm}$ ) $h$ increased. Conversely, when emissivity was calculated with soil moisture measured over a shallower layer, $h$ decreased.

Therefore, it is likely that the high dependency of roughness on soil moisture found in several studies devoted to validate models in the framework of the SMOS mission preparation can be attributed to the large sampling depth $(0-5 \mathrm{~cm})$ provided by widely used field moisture sensors.

In addition, the model roughness parameter was found to be sensitive to the moist soil dielectric model. Fig. 4 shows $h$ for the actual soil moisture sampling depth $\left(\Theta_{0-2} \mathrm{~cm}\right)$ for different dielectric models (Dobson, Wang and Mironov considered). When the Dobson model was used, $h$ slightly increased for dry soil moisture conditions. The reverse was found with the Wang model. The least dependency was found with the Mironov model. It seems that the roughness parameter performs a balance role for the differences between model and soil dielectric constant. The Mironov model would be thus the more adapted to that type of soil (loamy soil). Our results show that, when the most appropriate sampling depth and soil dielectric model are used, the sensitivity of the roughness parameter to soil moisture decreases, which is very convenient since it simplifies the parameterization of the soil emission.

The correlation between $h$ and $\sigma$ was very low $\left(R^{2}<0.3\right)$ whatever the soil moisture sampling depth or dielectric model indicating that the variations of $h$ cannot be attributed to $\sigma$ variations. This is explained by the fact that the SMOSREX field was very smooth at the time of the experiment and the change in $\sigma$ during the experiment

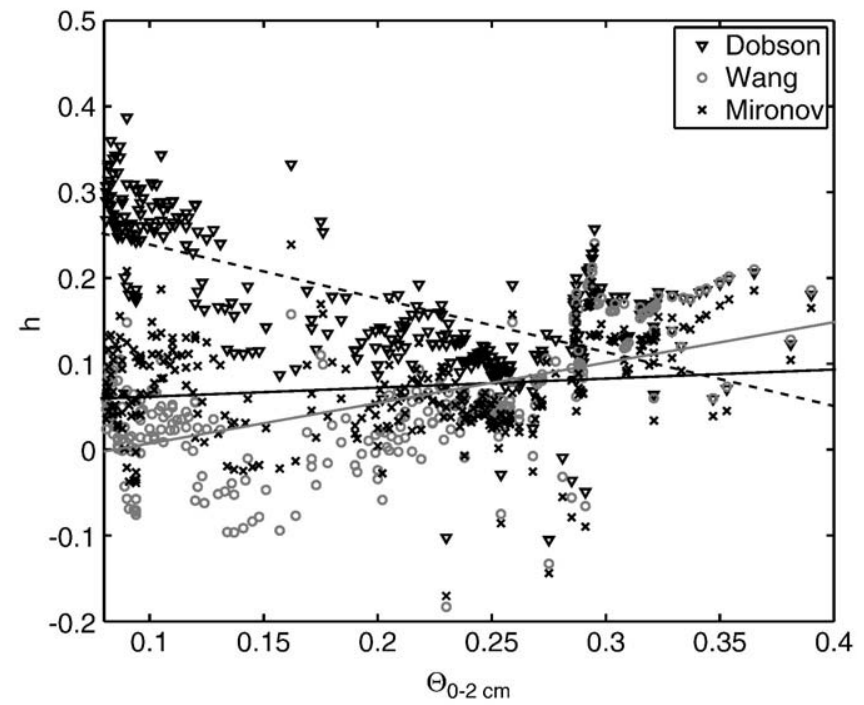

Fig. 4. Roughness model parameter $(h)$ sensitivity to soil moisture for different soil dielectric models (Dobson, Wang and Mironov). The estimated sampling depth $\Theta_{0-2 \mathrm{~cm}}$ is used to compute soil reflectivity in Eq. (7). Regression lines for Dobson (black discontinuous), Wang (grey) and Mironov (black) are also plotted. was probably not relevant in terms of emission. Note that this result has been tested in a very limited roughness range and it is probably different when a variety of roughness conditions are considered.

The brightness temperature was simulated through all the experiments with Eqs. (2), (6) and (7). In Eq. (7), $\Theta_{0-2 \mathrm{~cm}}$ was used to compute soil reflectivity. The soil dielectric constant was calculated with the Mironov model. An averaged constant roughness parameter ( $h=0.13$ ) was used in Eq. (7) in order to evaluate the error committed when considering a constant roughness parameter.

The simulated brightness temperature showed a very good agreement with measurements for all moisture conditions. The results for the horizontal polarized brightness temperature at $40^{\circ}$ incidence angle for a dry and a wet period during the experiment are shown in Fig. 5. The figure shows that there is a very good agreement concerning both the averaged value and diurnal amplitude of the brightness temperature.

There was a very good agreement between measurements and model except for brightness temperature values higher than $250 \mathrm{~K}$, which corresponds to values of soil moisture lower than $0.08 \mathrm{~m}^{3} \mathrm{~m}^{-3}$. In that particular case, there was a systematic underestimation of the mean brightness value and the diurnal variation of the simulated brightness temperature (see Fig. 6). Different modeling errors (effective temperature, TEC model) that could explain this behavior were analyzed. The use of the theoretical effective temperature
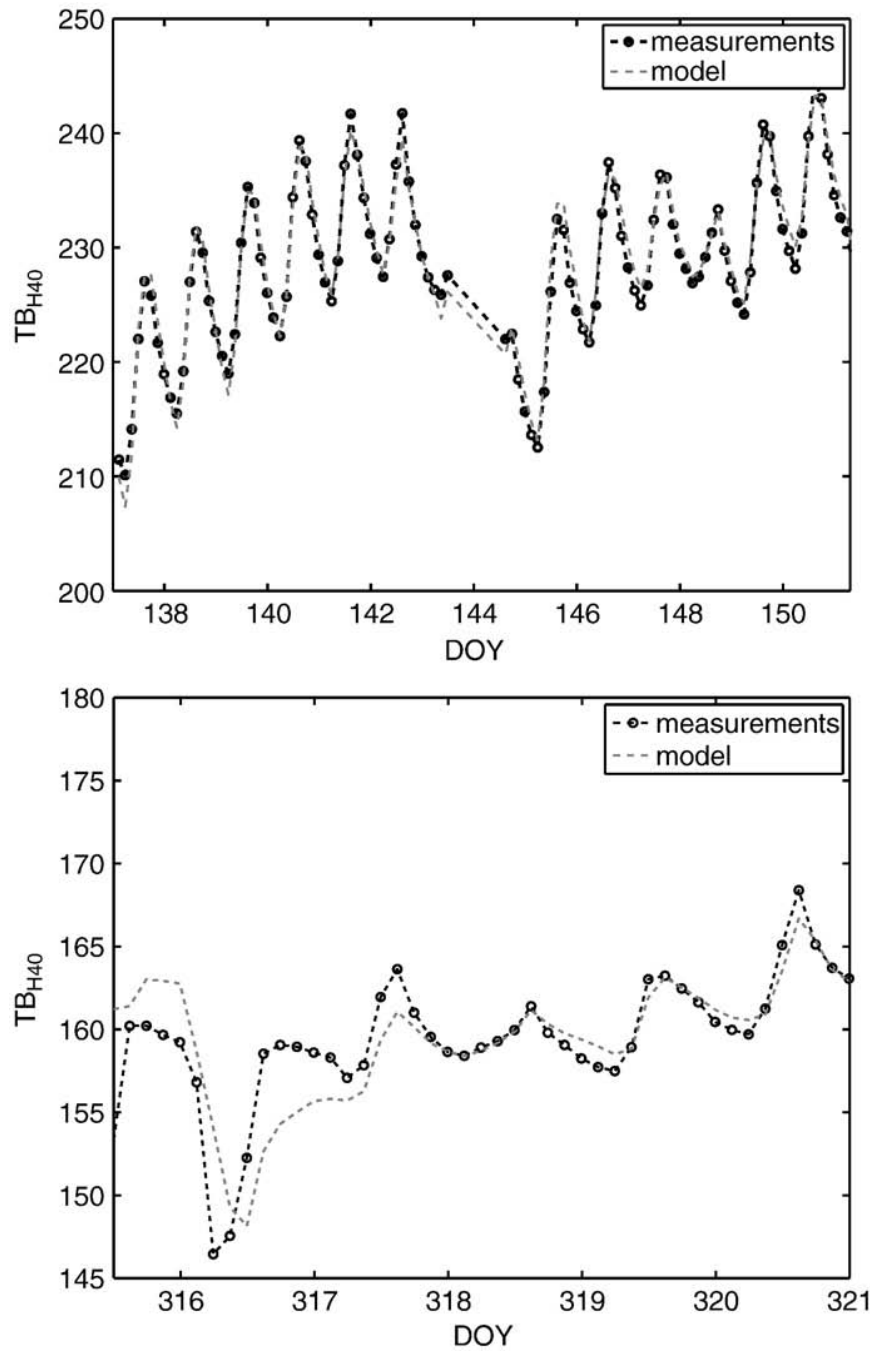

Fig. 5. Simulations of horizontal brightness temperature at $40^{\circ}$ incidence angle using a constant roughness parameter $h$, soil moisture sampling depth $\Theta_{0-2} \mathrm{~cm}$ and the Mironov model for a dry and a wet period during the experiment. 


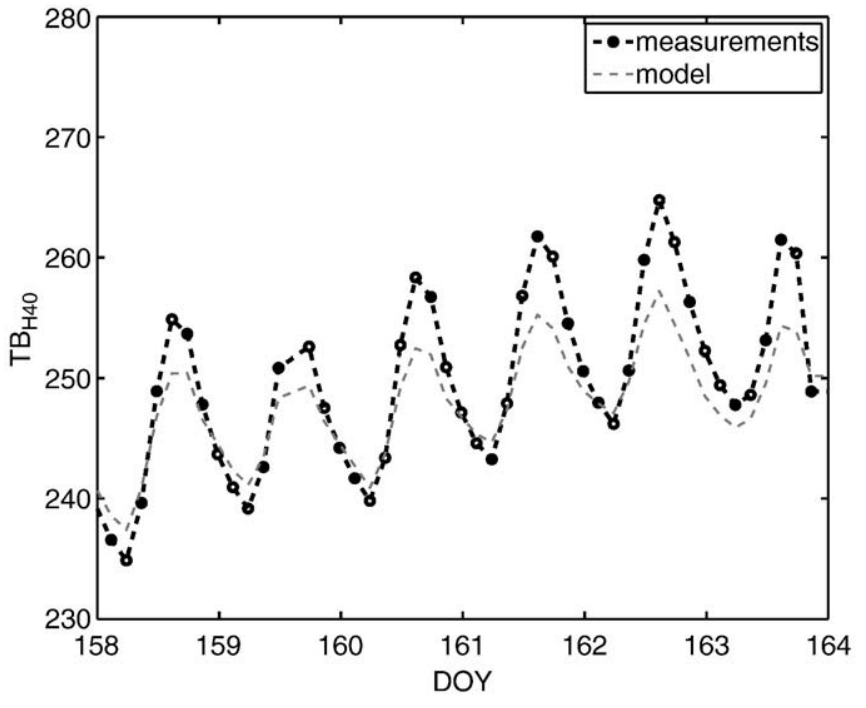

Fig. 6. Simulations of horizontal brightness temperature at $40^{\circ}$ incidence angle using a constant roughness parameter $h$, soil moisture sampling depth $\Theta_{0-2} \mathrm{~cm}$ and the Mironov model for an extremely dry period during the experiment.

(computed with Eqs. 3, 4 and 5) improved the estimations of brightness temperature by $0.1 \mathrm{~K}$, however the mean value and the diurnal amplitude of the modeled brightness temperature did not improve significantly and were always lower than measured. A systematic error of the TEC model, the model providing soil moisture values up to $0.02 \mathrm{~m}^{3} \mathrm{~m}^{-3}$ wetter than real conditions, could explain the underestimation of brightness temperature for extremely dry soil moisture conditions. This seems to be the most likely since, as it has already been shown in Fig. 2, the TEC model seems to saturate at extremely dry soil moisture conditions and values lower than $0.05 \mathrm{~m}^{3} \mathrm{~m}^{-3}$ are not produced.

Except for that particular case, there was a very good agreement with measurements. Fig. 7 shows the scatter plot for measurements and model horizontal polarized brightness temperature at $40 \mathrm{~K}$ through the experiment. The root mean squared error was $7.23 \mathrm{~K}$ and the correlation coefficient $\left(R^{2}\right)$ was 0.98 . When extremely dry soil moisture conditions were not considered the root mean squared error

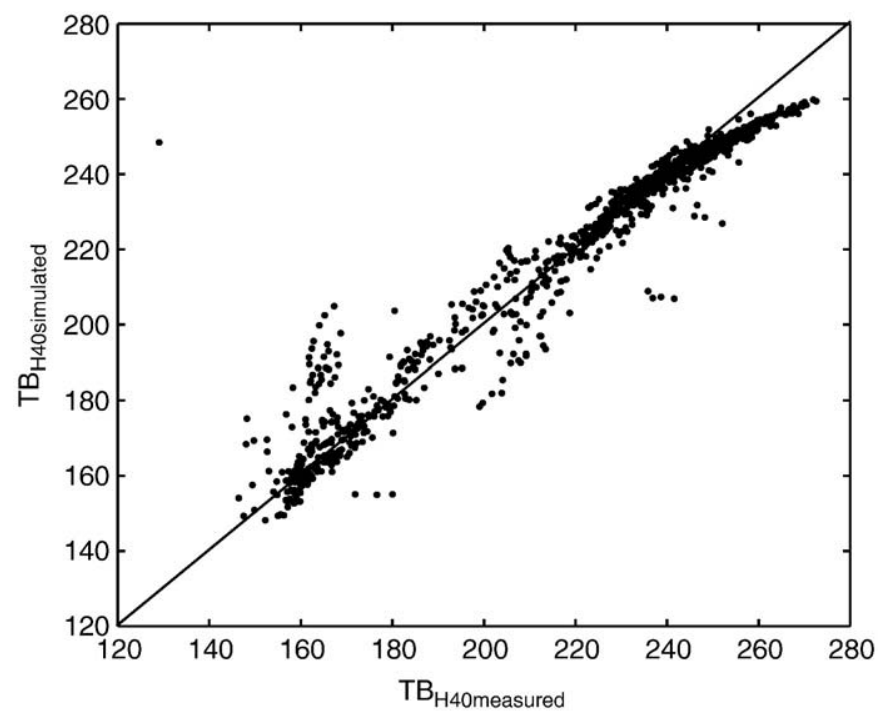

Fig. 7. Correlation between measurements and simulated horizontal brightness temperature at $40^{\circ}$ incidence angle using $\Theta_{0-2} \mathrm{~cm}$ as soil moisture sampling depth and the Mironov model to compute soil reflectivity. A constant value of roughness ( $h=0.13$ ) was considered. was $5.12 \mathrm{~K}$, which corresponds roughly to an error in soil moisture of $0.02 \mathrm{~m}^{3} \mathrm{~m}^{-3}$ (considering that at $1.4 \mathrm{GHz}$ soil moisture sensitivity over a bare soil is about $2.5 \mathrm{~K}$ per $0.01 \mathrm{~m}^{3} \mathrm{~m}^{-3}$ (Jackson \& Schmugge, 1991)).

\section{Conclusions}

The aim of this study was to analyze the influence of the soil moisture sampling depth in the parameterizations of soil emission in microwave radiometry at L-band. Radiometric, soil moisture and temperature measurements were performed over a bare soil. A more detailed profile of the surface soil moisture was obtained with a soil heat and water flows mechanistic model.

It was found that, when all incidence angles and polarizations were considered, the best correlation was obtained between the brightness temperature and soil moisture over the 0 to $2 \mathrm{~cm}$ surface layer. For dry soils, the best correlation was obtained between brightness temperature and soil moisture over the first $2 \mathrm{~cm}$ whereas for wet soils, the best correlation was between brightness temperature and soil moisture measured over the 0 to $1 \mathrm{~cm}$ surface layer. Soil moisture sampling depth would thus depend on soil moisture conditions. The drier the soil, the deeper the sampling depth.

During wet periods, no sensitivity of the estimated roughness parameter $h$ to the soil moisture depth was found. During dry periods, the roughness parameter increased as the soil moisture depth increased. When the actual sampling depth was used (i.e. about $2 \mathrm{~cm}$ ), a very low sensitivity of the estimated roughness parameter $h$ to soil moisture was found.

The estimated roughness parameter was also found to depend on the model used to compute the soil dielectric constant. Over our experimental site, when the Mironov model was used, $h$ was found to be almost constant for all soil moisture conditions.

Brightness temperature simulations performed with a constant sampling depth $(2 \mathrm{~cm})$ and a constant roughness parameter over a rather smooth soil showed very good agreement with measurements. The root mean squared error was $7.23 \mathrm{~K}$ and the correlation coefficient $\left(R^{2}\right)$ was 0.98 . When extremely dry soil moisture conditions were not considered the root mean squared error was as low as $5.12 \mathrm{~K}$.

This study shows evidence that, the strong dependency of the roughness parameter $h$ with soil moisture found in several studies devoted to validate models in the framework of the SMOS mission preparation is due to the large soil moisture sampling depth provided by widely used field sensors. In order to calibrate and validate remote sensing data at L-band it is thus recommended to measure surface soil moisture closer to the surface or to use a mechanistic model to estimate soil moisture over a shallower layer (close to $2 \mathrm{~cm}$ at L-band). The conclusions of this study are crucial for the calibration and validation of remote sensing data at L-band.

\section{References}

Calvet, J. -C., Fritz, N., Froissard, F., Suquia, D., Petitpa, A., \& Piguet, B. (2007). In situ soil moisture observations for the CAL/VAL of SMOS: The SMOSMANIA network. Proceedings Geoscience and Remote Sensing Symposium (pp. 1196-1199).

Chanzy, A., \& Bruckler, L. (1993). Significance of soil moisture with respect to daily bare soil evaporation. Water Resources Research, 29, 1113-1125.

Chanzy, A., Chadoeuf, J., Gaudu, J., Mohrath, D., Richard, G., \& Bruckler, L. (1998). Soil moisture monitoring at the field scale using automatic capacitance probes. European Journal of Soil Science., 49, 637-648.

Chanzy, A., Mumen, M., \& Richard, G. (2008). Accuracy of top soil moisture simulation using a mechanistic model with limited soil characterization. Water Resources Research, 44.

Choudhury, B., Schmugge, T., Chang, A., \& Newton, R. (1979). Effect of surface roughness on the microwave emission from soils. Journal of Geophysical Research, 5699-5706.

de Rosnay, P., Calvet, J. -C., Kerr, Y., Wigneron, J. -P., Lemaître, F., Escorihuela, M. J., et al. (2006). SMOSREX: A long term field campaign experiment for soil moisture and land surface processes remote sensing. Remote Sensing of Environment, 102, 377-389.

de Vries, D. A. (1963). Thermal properties of soils. In W. R. van Wijk (Ed.), Physics of plant environment (pp. 210-235). Amsterdam, Netherlands: North-Holland Publ. Co. 
Dobson, M., Ulaby, F., Hallikainen, M., \& El-Rayes, M. (1985). Microwave dielectric behaviour of wet soil- Part II: Dielectric mixing models. IEEE Transactions on Geoscience and Remote Sensing, 23, 35-47.

Escorihuela, M. J., de Rosnay, P., Kerr, Y., \& Calvet, J. -C. (2007a). Influence of bound water relaxation frequency on soil moisture measurements. IEEE Transactions on Geoscience and Remote Sensing, 45, 4067-4076.

Escorihuela, M. J., Kerr, Y., de Rosnay, P., Wigneron, J. -P., Calvet, J. -C., \& Lemaître, F. (2007b). A simple model of the bare soil microwave emission at L-band. IEEE Transactions on Geoscience and Remote Sensing, 45, 1978-1987.

Holmes, T., de Rosnay, P., de Jeu, R., Wigneron, J. -P., Kerr, Y., Calvet, J. -C., et al. (2006). A new parameterization of the effective temperature for L-band radiometry. Geophyical Research Letters, 33.

Jackson, T., \& Schmugge, T. (1991). Vegetation effects on the microwave emission of soils. Remote Sensing of Environment, 36, 203-212.

Kerr, Y. (2007). Soil moisture from space: Where we are? Hydrogeology Journal, 15, $117-120$.

Lemaître, F., Poussiere, J., Kerr, Y., Dejus, M., Durbe, R., de Rosnay, P., et al. (2004). Design and test of the ground based L-band radiometer for estimating water in soils (LEWIS). IEEE Transactions on Geoscience and Remote Sensing, 42, 1666-1676.

Merlin, O., Walker, J., Kalma, J., Kim, E., Hacker, J., Panciera, R., et al. (2008). The NAFE'06 data set: Towards soil moisture retrieval at intermediate resolution. Advance Water Research, 31, 1444-1455.

Mironov, V., Dobson, M., Kaupp, V., Komarov, S., \& Kleshchenko, V. (2004). Generalized refractive mixing dielectric model for moist soils. IEEE Transactions on Geoscience and Remote Sensing, 42, 773-785.
Panciera, R., Walker, J., Kalma, J., Kim, E., Saleh, K., \& Wigneron, J. -P. (2009). Evaluation of the SMOS L-MEB passive microwave soil moisture retrieval algorithm. Remote Sensing of Environment, 435-444.

Pellarin, T., Wigneron, J., Calvet, J. C., Berger, M., Douville, H., Ferrazzoli, P., et al. (2003). Two-year global simulation of L-band brightness temperature over land. IEEE Transactions on Geoscience and Remote Sensing, 41(4), 2135-2139.

Raju, S., Chanzy, A., Wigneron, J., C.J., Kerr, Y., \& Laguerre, L. (1995). Soil moisture and temperature profile effect on microwave emission at low frequencies. Remote Sensing of Environment, 54, 85-97.

Saleh, K., Kerr, Y., Richaume, P., Escorihuela, M., Panciera, R., Delwart, S., et al. (2009). Soil moisture retrievals at L-band using a two-step inversion approach (COSMOS/ NAFE'05 Experiment). Remote Sensing Environment, 113, 1304-1312.

Saleh, K., Wigneron, J. -P., de Rosnay, P., Calvet, J. -C., Escorihuela, M. J., Kerr, Y., et al. (2006). Impact of rain interception by vegetation and mulch on the L-band emission of natural grass. Remote Sensing Environment, 101, 127-139.

Ulaby, F., Moore, R., \& Fung, A. (1986). Microwave remote sensing: Active and passive, Vol III, from theory to application. Dedham, MA: Artech House.

Wang, J., \& Schmugge, T. (1980). An empirical model for the complex dielectric permittivity of soils as a function of water content. IEEE Transactions on Geoscience and Remote Sensing, 18, 288-295.

Wang, J. R. (1987). Microwave emission from smooth bare fields and soil moisture sampling depth. Remote Sensing Environment, 25, 616-622.

Wigneron, J., Laguerre, L., \& Kerr, Y. (2001). A simple parameterization of the L-band microwave emission from rough agricultural soils. IEEE Transactions on Geoscience and Remote Sensing, 39, 1697-1707. 